\title{
Anatomic characterisation of the parietal branches arising from the internal iliac artery in the foetal pig (Sus scrofa domestica)
}

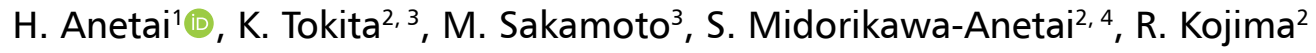 \\ 'Department of Anatomy and Life Structure, School of Medicine, Juntendo University, Tokyo, Japan \\ ${ }^{2}$ School of Physical Therapy, Faculty of Health and Medical Care, Saitama Medical University, Saitama, Japan \\ ${ }^{3}$ Graduate School of Medicine, Saitama Medical University, Saitama, Japan \\ ${ }^{4}$ Graduate School of Agricultural and Life Sciences, the University of Tokyo, Japan
}

[Received: 16 May 2020; Accepted: 11 July 2020; Early publication date: 29 July 2020]

Background: It is critical for surgeons to have a full understanding of the complex courses and ramifications of the human internal iliac artery and its parietal branches. Although numerous anatomical studies have been performed, not all variations at this site are currently understood. Therefore, we characterised these blood vessels in foetal pigs to provide additional insight from a comparative anatomical perspective.

Materials and methods: Eighteen half-pelvis specimens from foetal pigs were dissected and examined on macroscopic scale.

Results: Among our findings, we identified the internal iliac artery as a descending branch of the abdominal aorta. A very thick umbilical artery arose from the internal iliac artery. The superior gluteal, inferior gluteal, and internal pudendal arteries formed the common arterial trunk. Although the superior gluteal artery emerged from the common trunk from inside the pelvis, the inferior gluteal and internal pudendal arteries bifurcated at deep layer within the gluteus muscles after leaving pelvic cavity. We were unable to detect an typical obturator artery emerging from the internal iliac artery. A branch supplying the hip adductors was identified as arising from the inferior epigastric artery which itself was derived from the distal end of the external iliac artery.

Conclusions: We identified the anatomic characteristics of the internal iliac artery and its parietal branches in the foetal pig. Our findings provide new insight into the comparative anatomy of the internal iliac artery and will promote understanding of related morphogenetic processes. (Folia Morphol 2021; 80, 3: 549-556)

Key words: hypogastric artery, pelvic artery, gross anatomy, comparative anatomy, anatomical variation, domestic animal

\section{INTRODUCTION}

The internal iliac artery arises from a bifurcation of the common iliac artery which generates numerous branches that feed the gluteal region, the medial compartment of thigh, and the intrapelvic viscera in humans $[14,15,18,26]$. These branches are classified into two groups on the basis of the pattern of blood supply (Table 1). Group 1 includes the parietal

Address for correspondence: Mr. H. Anetai, Department of Anatomy and Life Structure, School of Medicine, Juntendo University, 2-1-1 Hongo, Bunkyo-ku, Tokyo 113-8421, Japan, tel: +81-3-5802-1023, fax: +81-3-5689-6923, e-mail: h-anetai@juntendo.ac.jp

This article is available in open access under Creative Common Attribution-Non-Commercial-No Derivatives 4.0 International (CC BY-NC-ND 4.0) license, allowing to download articles and share them with others as long as they credit the authors and the publisher, but without permission to change them in any way or use them commercially. 
Table 1. General anatomy of the parietal and visceral branches of the human internal iliac artery

\begin{tabular}{|c|c|c|}
\hline Group & Artery & Main blood supply \\
\hline \multirow[t]{6}{*}{ Parietal branch } & Superior gluteal artery & Gluteal muscles \\
\hline & Inferior gluteal artery & Gluteal muscles \\
\hline & Internal pudendal artery & $\begin{array}{l}\text { Parietal wall of } \\
\text { ischio-anal fossa }\end{array}$ \\
\hline & Obturator artery & Hip adductor muscles \\
\hline & lliolumbar artery & Intrapelvic muscles \\
\hline & Lateral sacral artery & Spinal cord \\
\hline \multirow[t]{5}{*}{ Visceral branch } & (Cord of) umbilical artery & - \\
\hline & Superior vesical arteries & Urinary organs \\
\hline & Inferior vesical arteries & Urinary organs \\
\hline & $\begin{array}{c}\text { Artery to ductus } \\
\text { deferens/uterine artery }\end{array}$ & Internal genitalia \\
\hline & Middle rectal artery & Rectum \\
\hline
\end{tabular}

branches, which are the arteries that feed the parietal muscles, e.g., the gluteal and hip adductor muscles. Group 2 are the visceral branches that provide blood supply to the intrapelvic organs, including the internal genitalia, urinary organ, and the rectum. The superior gluteal (SG), iliolumbar and lateral sacral arteries typically arise from the posterior division of the internal iliac artery, while all other branches originate from the anterior division $[15,18]$.

The ramifications and courses characteristic of these branches of the internal iliac artery can be quite complex in human subjects, and there are many published studies that survey the anatomy of this region $[1,2,8,9,17,23,24,27,30,32,36,39,41,42]$. The anomalies identified in the main parietal branches, the SG, inferior gluteal artery (IG), internal pudendal artery (IP), and obturator artery (Ob) have been a subject of great interest among anatomists and clinicians due to their morphological and surgical significance.

In the past few years, morphogenetic and topographic studies focused on the origin and course of variations identified among the parietal branches of the internal iliac artery have been subjected to conventional statistical analyses. As but one example, Honma et al. [17] examined the formation of an arterial ring in the human pelvic artery and suggested that specific ramifications of the parietal branches were associated with the site of disappearance of the arterial ring. Furthermore, previous study examined variations in the course taken by the SG, including its relationship with the lumbosacral plexus; we found that the route taken by the SG varied in accordance with the segmental variations of the lumbosacral plexus [4]. However, not all anatomical variations among the parietal branches are clearly understood; for example, the branching patterns and course variations observed among the IG and Ob have not been fully considered.

There are very few published studies that focus on embryologic and comparative anatomical descriptions of anomalies of the internal iliac artery and its parietal branches; likewise, precise embryological and anatomical descriptions of the internal iliac artery during foetal development have not been reviewed since 1919 [35]. Anatomic investigations of the internal iliac artery have been conducted in a several primate, rodent, and artiodactyl species, although very few comparative studies have emerged $[2,6$, $13,16,21,22]$. As such, it is clear that the standard anatomy of the internal iliac artery with respect to commonalities shared with other mammalian species has not been fully addressed; strong basic findings would be crucial prior to any discussion of variations or aberrancies. In the present study, our goal was to identify the anatomical characteristics of the parietal branch arising from the internal iliac artery in a foetal pig (Sus scrofa domestica). This would be an important first step toward systematising all available information on the standard structure of the common parietal branches as well as the identification of specific findings characteristic of each species.

\section{MATERIALS AND METHODS}

The present study performed in 18 half-pelvis specimens (12 right and 6 left) from foetal pigs (Sus scrofa domestica) which had been used for anatomical studies as part of the curriculum of the Department of Physical Therapy, Faculty of Health and Medical Care, Saitama Medical University. In the present study, experiments involving animals were carried out in accordance with the Guidelines for Proper Conduct of Animal Experiments (Science Council of Japan), as revised in 2006 .

All specimens were obtained as scientific teaching materials from Bio Corporation (Alexandria, MN, USA) and were embalmed with $1.8 \%$ formalin, $2.7 \%$ phenol, and $5.0 \%$ ethylene glycol. Additionally, the specimens were injected with red latex in the arterial systems. The distance between the crown and rump of the specimens was $30-35 \mathrm{~mm}$.

The internal iliac artery and its parietal branches were identified through conventional macroscopic dissection procedures. The origin, course and dis- 


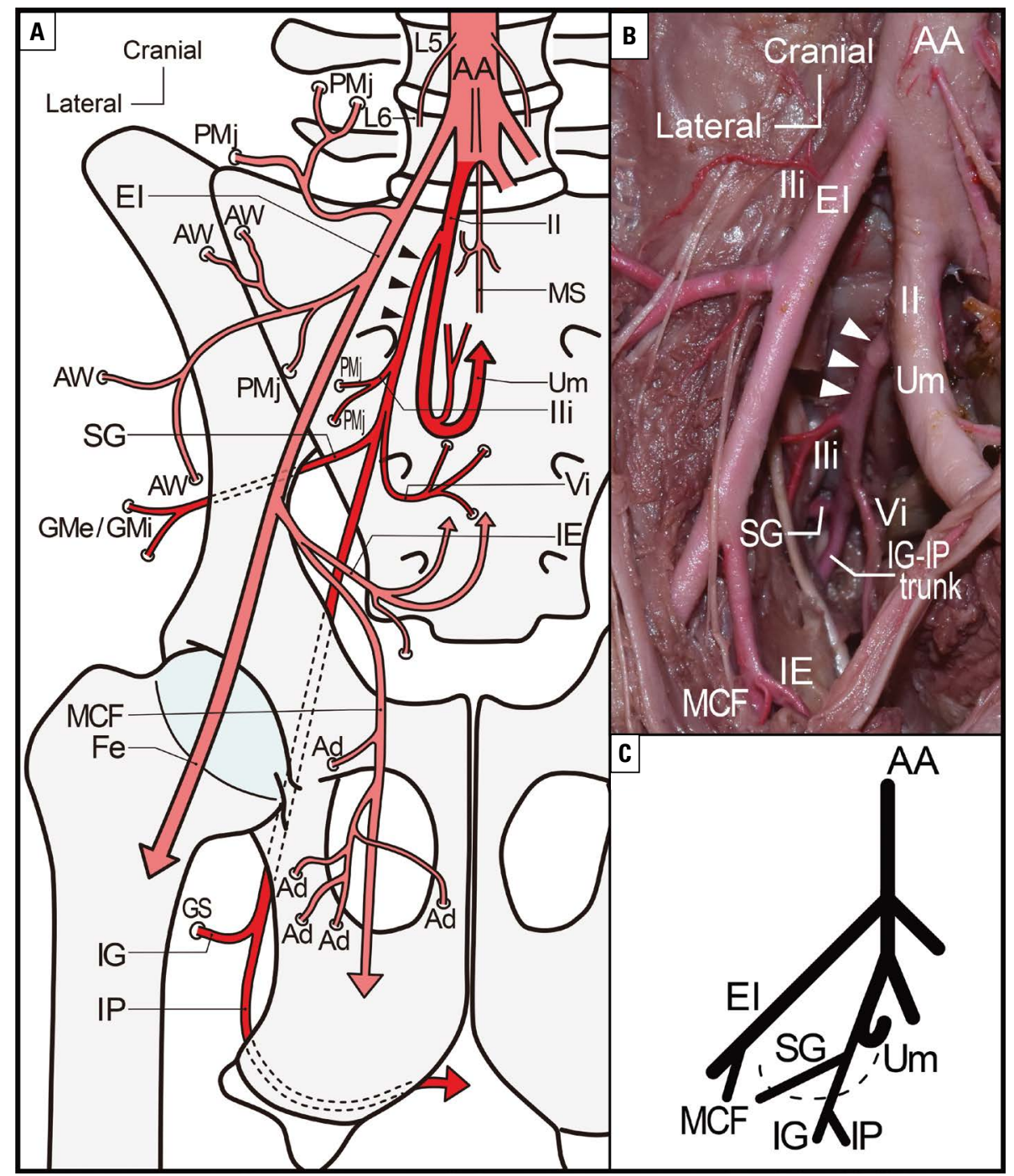

Figure 1. Typical ramification and branches from the iliac artery; A. Drawing of the iliac artery and peripheral structures in the foetal pig. The internal iliac artery and its branches are shown in bright red; B. Photograph of a dissected right iliac artery and peripheral structures in the foetal pig; C. Schematic of the arterial tree of dissected right iliac artery in the foetal pig. Black and white arrowheads indicate the common arterial trunk formed by the superior gluteal artery (SG), inferior gluteal artery (IG), and internal pudendal artery (IP). The dotted line indicates the outlet of the pelvic cavity; AA — abdominal aorta; $\mathrm{Ad}$ - hip adductor muscles; AW - abdominal wall; EI external iliac artery; $\mathrm{Fe}$ - femoral artery; $\mathrm{GMe}$ - gluteus medius; $\mathrm{GMi}$ - gluteus minimus; GS - gluteus superficialis; $\mathrm{IE}$ - inferior epigastric artery; II - internal iliac artery; lli iliolumbar artery; L — lumbar vertebra; MCF — medial circumflex femoral artery; MS — medial sacral artery; $\mathrm{PMj}$ psoas major; Um — umbilical artery; $\mathrm{Vi}$ - visceral branch. tribution of the all parietal branches were recorded by accurate sketches and photographs that were organised following the classifications described by Adachi [1] and Yamaki et al. [42].

\section{RESULTS}

Ramifications of the iliac artery

In all cases examined, the external and internal iliac arteries arose directly from the abdominal aorta at the level of the last lumbar vertebra; there was no blood vessel corresponding to the common iliac artery in the foetal pig. The internal iliac artery descended from its point of origin into the pelvic cavity and then generated several branches. Its ramifications and the courses of several parietal branches were as shown in Figure 1. Of all branches, the umbilical artery extended from the internal iliac artery with a strong and consistent pattern. This artery first descended, and turned toward the umbilicus and ascended.

\section{Ramifications, course, and distributions} of SG, IG, and IP

In all 18 half-pelvis specimens, the SG, IG, and IP were the three main parietal branches that form the common arterial trunk (black and white arrowheads in Fig. 1A, B) that emerged from the internal iliac artery. The SG emerged from the common arterial trunk as an oblique descending branch. In the 15 of 18 specimens examined, the SG passed through the upper part of the sacral plexus, below the lumbosacral trunk and the suprapiriform foramen to reach gluteal muscles ("a" in Fig. 2 and Table 2). The relation of the SG course to the sacral plexus was nearly constant even in cases in which the root of the plexus shifted cranially or caudally due to a smaller or larger number of thoracolumbar vertebrae (Table 2).

The arterial trunk of the remaining two branches, the IP-IG trunk, descended and passed through the infrapiriform foramen to appear outside the pelvis. 


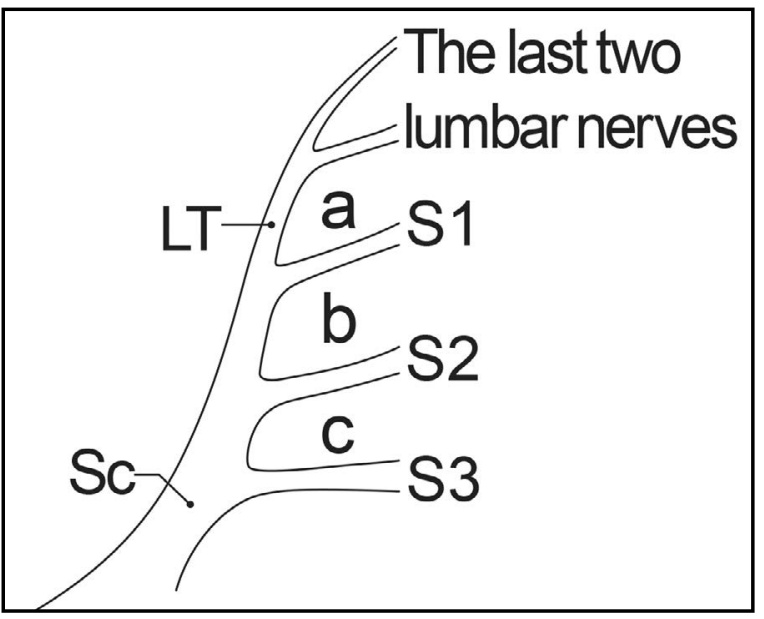

Figure 2. Positional relation of the gluteal artery route to the sacral plexus. The superior gluteal artery (SG) passed through the upper (a) or occasionally the middle part (b) of the sacral plexus. The lower part of the plexus was intersected by the atypical gluteal artery (c). The lumbosacral trunk consistently originated from the last two lumbar nerves; LT — lumbosacral plexus; $\mathrm{S}$ - root of the sacral nerves; Sc - sciatic nerve.

After leaving the pelvic cavity, the common arterial trunk divided immediately into two branches; the IG provided blood supply to the gluteus superficialis muscle from the deep surface along with the inferior gluteal nerve and the IP entered into the pudendal canal together with the pudendal nerve.

The origin, course, and distribution of the $\mathrm{Ob}$

There was no Ob originating from the internal iliac artery. Although this artery as an extremely slender branch was occasionally detected as emerging from the common trunk or iliolumbar artery and descending toward the obturator foramen, it did not reach the obturator foramen and the hip adductors. Meanwhile, an arterial branch supplying blood to the hip adductor muscles, similar to the human $\mathrm{Ob}$, was found to be arising from the inferior epigastric artery which extended from distal end of the external iliac artery (Fig. 1). This artery passed under the inguinal ligament and extended around hip adductors. Most of cases exhibited this single-branch anatomy save a few cases that exhibited two branches; this branch corresponded to the medial circumflex femoral artery that extended from the deep femoral artery observed generally in veterinary anatomy [28].

\section{Other minor parietal branches}

The iliolumbar artery arose from either the external and internal iliac arteries, and included multiple

Table 2. Number of thoracolumbar vertebra, origin of the lumbosacral trunk, and the course of the superior gluteal artery (SG), refer to Figure 2, in all 18 cases examined

\begin{tabular}{|c|c|c|c|c|c|}
\hline \multirow[t]{2}{*}{ Specimen number } & \multicolumn{2}{|c|}{ Number of vertebrae } & \multirow{2}{*}{$\begin{array}{c}\text { Total number of } \\
\text { thoracolumbar vertebrae }\end{array}$} & \multirow{2}{*}{$\begin{array}{c}\text { Origin of the lumbosacral } \\
\text { trunk }\end{array}$} & \multirow[t]{2}{*}{ SG course } \\
\hline & Thoracic & Lumbar & & & \\
\hline 1 & 15 & 7 & 22 & & a \\
\hline 2 & 15 & 7 & 22 & & a \\
\hline 3 & 15 & 6 & 21 & & a \\
\hline 4 & 15 & 6 & 21 & & a \\
\hline 5 & 15 & 6 & 21 & & a \\
\hline 6 & 15 & 6 & 21 & & a \\
\hline 7 & 14 & 6 & 20 & & a \\
\hline 8 & 16 & 6 & 22 & & a \\
\hline 9 & 16 & 6 & 22 & All originated from & $b$ \\
\hline 10 & 14 & 7 & 21 & the last two lumbar nerves & a \\
\hline 11 & 14 & 7 & 21 & & $b$ \\
\hline 12 & 14 & 7 & 21 & & $b$ \\
\hline 13 & 14 & 8 & 22 & & a \\
\hline 14 & 15 & 7 & 22 & & a \\
\hline 15 & 15 & 7 & 22 & & $\mathrm{a}$ \\
\hline 16 & 15 & 7 & 22 & & $a$ \\
\hline 17 & 16 & 6 & 22 & & $a$ \\
\hline 18 & 16 & 7 & 23 & & $a$ \\
\hline
\end{tabular}




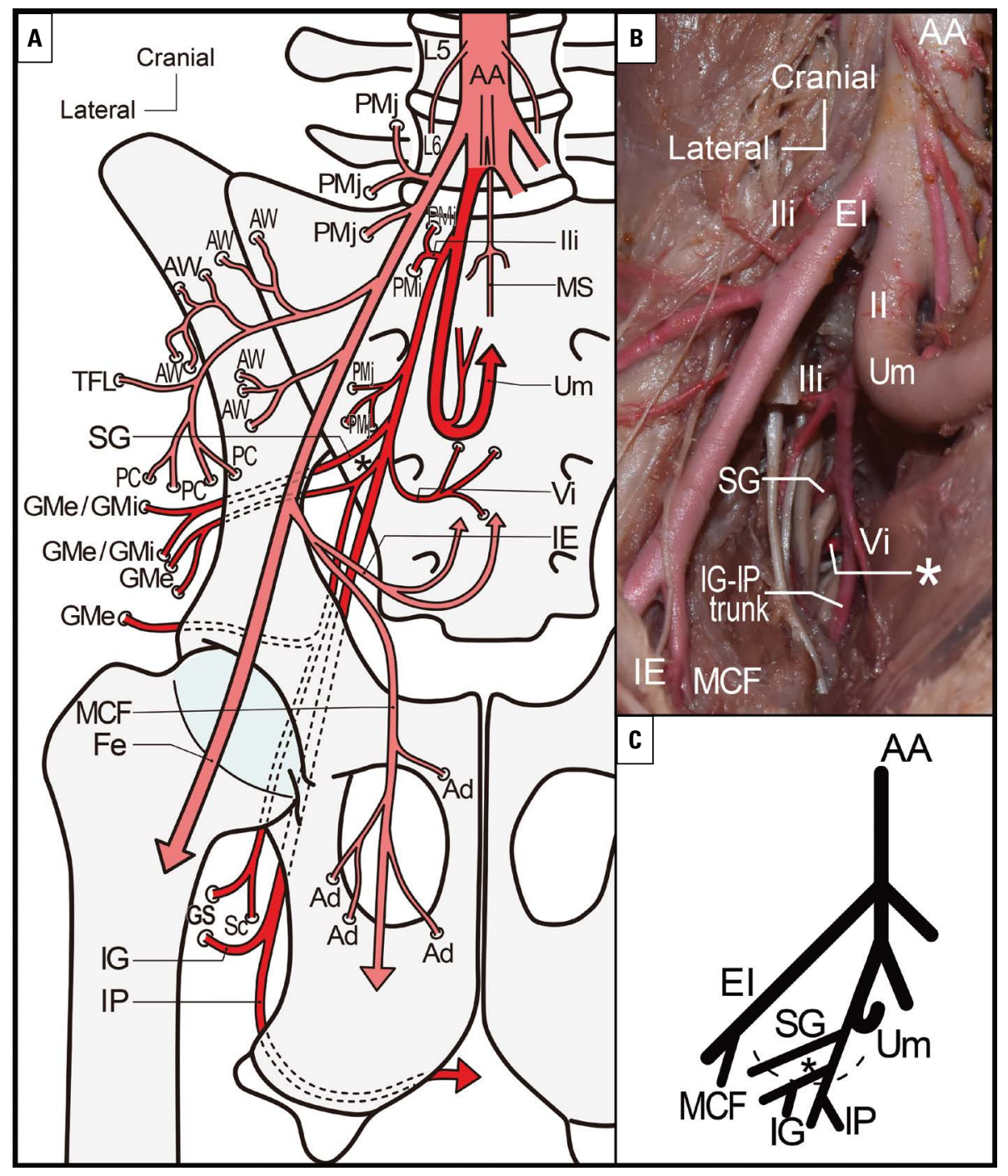

Figure 3. Atypical ramification and branches from the iliac artery; A. Drawing of right iliac artery and peripheral structures in the foetal pig. The internal iliac artery and its branches are shown in red; B. Photograph of the right iliac artery and peripheral structures in the foetal pig; C. Schematic of the arterial tree of the iliac artery in the foetal pig. Black and white asterisks denote the atypical gluteal artery. The dotted line shows the outlet of the pelvic cavity;

AA — abdominal aorta; Ad — hip adductor muscles; AW - abdominal wall; EI external iliac artery; $\mathrm{Fe}$ - femoral artery; $\mathrm{GMe}$ - gluteus medius; $\mathrm{GMi}$ - gluteus minimus; GS - gluteus superficialis; IE — inferior epigastric artery; IG — inferior gluteal artery; II — internal iliac artery; Ili iliolumbar artery; IP — internal pudendal artery; $\mathrm{L}$ - lumbar vertebrae; MCF - medial circumflex femoral artery; MS medial sacral artery; PC — panniculus carnosus; $\mathrm{PMi}$ - psoas minor; $\mathrm{PMj}$ - psoas major; Sc - sciatic nerve; SG superior gluteal artery; TFL — tensor fasciae lata; Um - umbilical artery; $\mathrm{Vi}$ - visceral branch.

branches that provided blood supply to the psoas major, psoas minor, and iliacus muscles. The iliolumbar artery emerged from the common arterial trunk as a first branch and had a tendency to pass above or below the lumbosacral trunk.

Although the medial sacral artery arose from the posterior division of the lower end of the abdominal aorta as a well-developed long descending branch, the lateral sacral artery was absent.

\section{Atypical gluteal artery}

Of the 18 specimens examined, we identified 1 case with a second gluteal artery (black and white asterisks in Fig. 3A, B). In this case, the SG emerged from the common arterial trunk after the iliolumbar artery and a second gluteal artery was detected immediately distal to this point from remaining descending branch. The SG passed through the middle sacral plexus, between the ventral rami of S1 and S2 spinal roots ("b" in Fig. 2 and Table 2), and through the suprapiriform foramen to reach the gluteus muscles. By contrast, the atypical gluteal artery passed through the lower part of the sacral plexus, between the spinal roots of S2 and S3 ("c" in Fig. 2) as well as the suprapiriform foramen. After leaving the pelvic cavity, the atypical branch bifurcated immediately; one branch provided blood supply to the gluteus medius and the other distributed blood to the gluteus medius, gluteus superficialis muscles, and sciatic nerve (Fig. 3A). In this case, the IG and IP arose at the bifurcation of the IG-IP trunk after leaving the pelvic cavity as was typical for the 18 foetal pig specimens examined.

\section{DISCUSSION}

\section{Origin of the parietal branch in the foetal pig}

In the present study, the patterns of several parietal branches arising from the internal iliac artery were evaluated in the foetal pig. In all specimens, the SG, 
IG, and IP formed the common descending trunk; the SG emerged from the common arterial trunk in the pelvic cavity. Meanwhile, the remaining IG-IP trunk bifurcated into the IG and IP after leaving the pelvic cavity. This branching pattern observed in the foetal pig corresponds to type IV as classified by Adachi in his study of the human internal iliac artery [1], although Adachi's classification did not consider whether the trunk bifurcates to the IG and IP at a location inside or outside of pelvic cavity. According Yamaki's modification of Adachi's classification system, this pattern of ramification corresponds to type IV/group 4 and is detected in only $0.5 \%$ of human subjects [42]. Although several branching patterns of human internal iliac artery have been examined based on the morphogenetic analysis of the specific case of arterial ring formation, type IV/group 4 is an exception [17].

The IG has been identified as a persistent axial artery (which corresponds to the sciatic artery) in the lower extremity that develops in the primordial stage $[5,7,12,34,35,43]$. The bifurcation of the common arterial trunk outside of pelvis reflects the fact that the IP originates from the IG. The IP originated from the IG in $40-90 \%$ in humans and there are remarkable variations among ethnic groups and specific published reports $[1,3,9,23,32,39]$. Interestingly, in the ground squirrel (Citellus citellus), the IP originates from the external iliac artery [6]. To understand the branching patterns of the common arterial trunk formed by the IG and IP, it is clearly crucial to establish the origin of the IP.

\section{Course of the SG}

The SG typically passed through the upper sacral plexus, below the lumbosacral trunk; this is the case even if the root of the plexus and the lumbosacral trunk shift cranially or caudally due to a smaller or larger number of thoracolumbar vertebrae (Fig. 2, Table 2). We suggest that this observation implies that the course taken by the SG relates directly to the observed segmental variations in the plexus including the lumbosacral trunk; this observation reflects similar findings from human cadaveric dissections [4].

\section{The atypical gluteal artery}

The atypical gluteal artery arose from the descending common arterial trunk after the emergence of the typical SG; it passed through the lower part of the sacral plexus and between the spinal roots of S2 and S3 (Fig. 2). This artery distributed blood to the gluteus medius, gluteus superficialis muscles, and sciatic nerve after emerging from the suprapiriform foramen and dividing into two branches (Fig. 3A). According to its origin, course, and distribution, this atypical artery has the anatomical characteristics that are similar to those both the SG and the IG. However, the fact that it supplies the sciatic nerve indicates that this atypical artery corresponds more closely to the IG, because the artery feeding the sciatic nerve has been identified as a persistent form of the sciatic artery which was present in the primordial stages prior to birth $[14,18]$. Analysis of this and other atypical cases may help toward our understanding of the morphogenesis of the sciatic artery.

\section{Comparative anatomy of the internal iliac artery and its main parietal branches}

The anatomy of the iliac artery has been evaluated in a several primate, artiodactyl, and rodent species; we have summarised the ramification patterns in Figure 4. As shown, the common iliac artery is absent in foetal pigs and llamas (Lama glama) [16], both of which belong to Artiodactyla. Although absence of the common iliac artery has been reported in human subjects, this anomaly is extremely rare $[10,25,37]$. Interestingly, aplasia of the common iliac artery has also been observed in other artiodactyls, including sheep (Ovis aries) and pampas deer (Ozotoceros bezoarticus) $[11,40]$ and as such, appears to be a phylogenetically defined phenomenon.

In both primates and rodents, the common iliac artery bifurcates into the external and internal iliac arteries (Fig. 4B, C). The SG has a tendency to emerge from the iliac artery before other main parietal branches; this branching pattern may reflect the fact that the SG originates from a root of the sciatic artery in humans during foetal development [35].

The IG and IP are frequently detected together and form the common arterial trunk; however, the IP can originate from the external iliac artery, as described above for ground squirrels. In progressive stage of human development in utero, the sciatic artery (which corresponds to the IG) and the IP were derived from a posterior division of the umbilical artery while the external iliac artery originates from the proximal part of the umbilical artery at a site in close proximity to the origin of the sciatic artery [35]. Therefore, the IP could originate from the IG and proximal part of the external iliac artery.

The medial circumflex femoral artery in the foetal pig provided blood to the hip adductors in place of the Ob. The medial circumflex femoral artery arose 


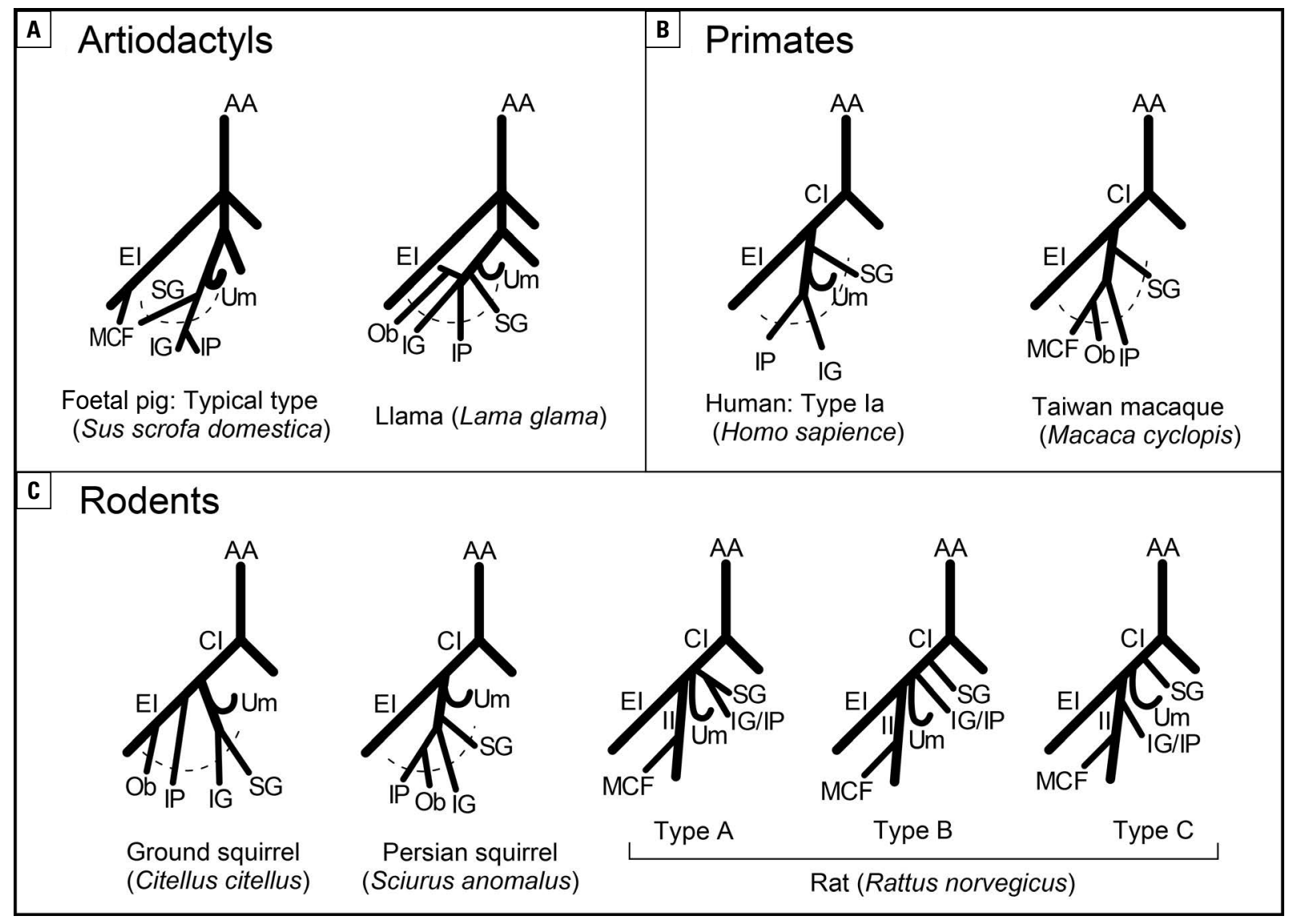

Figure 4. Summary of the ramification pattern of the iliac artery in several mammals including artiodactyls (A), primates (B), and rodents (C). Modified schematics of arterial tree of the internal iliac artery in each species, the foetal pig (present study), Llama (Graziotti, 2003), Human (Adachi, 1928), Taiwan macaque (Fujita, 1963), Ground squirrel (Blagojevic, 2013), Persian squirrel (Akibari, 2016) and Rat (Kigata and Shibata, 2019) are shown. The dotted line shows the outlet of the pelvic cavity; $\mathrm{AA}$ - abdominal aorta; $\mathrm{Cl}$ - common iliac artery; El — external iliac artery; II — internal iliac artery; IG — inferior gluteal artery; IP — internal pudendal artery; MCF — medial circumflex femoral artery; 0 - obturator artery; SG — superior gluteal artery; Um — umbilical artery.

from the inferior epigastric artery, and reached the hip adductors without passing through the obturator foramen. The inferior epigastric artery has a close morphogenetic relationship with the $\mathrm{Ob}$, and the origin of the medial circumflex femoral artery in the foetal pig is similar to "corona mortis" which is wellknown to surgeons as a prominent and significant anatomic variation of the human Ob [19, 20, 29, $31,33,38]$. Furthermore, in rats, the origin of the medial circumflex femoral artery is similar to that in a typical human Ob (Fig. 4C). Therefore, a more careful evaluation of the anatomical characteristics of the medial circumflex femoral artery in non-human mammals may help in understanding the variations in the human $\mathrm{Ob}$ including the corona mortis.

\section{CONCLUSIONS}

These findings in the present study can represent an important addition to the anatomical research into variations in the internal iliac artery. These findings will help us to understand the morphogenetic process and will be useful for surgical treatment of domestic animals.

\section{Acknowledgements}

This work was performed as a project study of the Faculty of Health and Medical Care, Saitama Medical University, Saitama, Japan. The authors would like to thank Enago (www.enago.jp) for the English language review.

\section{Conflict of interest: None declared}

\section{REFERENCES}

1. Adachi B. Das arteriensystem der Japaner. Bd. 2. Die Kaiserlich Japanische Universität zu Kyoto, Kyoto 1928.

2. Akibari G, Gilanpour $H$, Babaei M. The arterial pattern of terminal branch of the abdominal aorta in the male Persian squirrel (sciurus anomalus). Anat Sci. 2016; 13(2): 119-124. 
3. Akshara VR, Minnie PA. study on the variations of the branching pattern of the internal iliac artery. Int J Sci Res. 2014; 3(9): 723-725.

4. Anetai H, Tokita K, Kojima R, et al. Variations in the course of the superior gluteal artery in relation to the lumbosacral plexus. Okajimas Folia Anat Jpn. 2017; 94(2): 45-54, doi: 10.2535/ofaj.94.45, indexed in Pubmed: 29249733.

5. Arey L. Developmental Anatomy. WB Saunders, Philadelphia 1956.

6. Blagojevic $\mathrm{M}$, Nesic I, Djelic $\mathrm{N}$, et al. The common iliac artery in the ground squirrel (Citellus citellus). Acta Veterinaria. 2013; 63(4): 463-470, doi: 10.2298/avb1304463b.

7. Blair CB, Nandy K. Persistence of the axis artery of the lower limb. Anat Rec. 1965; 152(2): 161-172, doi: 10.1002/ ar.1091520207, indexed in Pubmed: 5842159.

8. Bleich AT, Rahn DD, Wieslander CK, et al. Posterior division of the internal iliac artery: Anatomic variations and clinical applications. Am J Obstet Gynecol. 2007; 197(6): 658. e1-658.e5, doi: 10.1016/j.ajog.2007.08.063, indexed in Pubmed: 18060970.

9. Braithwaite JL. Variations in origin of the parietal branches of the interanl iliac artery. J Anat. 1952; 86: 423-430.

10. Dabydeen DA, Shabashov A, Shaffer K. Congenital absence of the right common iliac artery. Radiol Case Rep. 2008; 3(1): 47-51, doi: 10.2484/rcr.v3i1.47, indexed in Pubmed: 27303500.

11. Elmetwally MA. Uterin blood flow indices in sheep during pregnancy. Qual Prim Care. 2016; 24(4): 197-202.

12. Esaki T, Oka N, Tsurumaru H, et al. A case of a developmental anomaly of the femoral artery: persistent sciatic artery. Jpn J Surg. 1980; 10(1): 72-76, doi: 10.1007/BF02468651, indexed in Pubmed: 7373956.

13. Fujita J. Pelvic arteries in macacus cyclopsis. I. The common iliac artery and the external iliac artery. Okajimas Folia Anat Jpn. 1963; 39: 85-116, doi: 10.2535/ofaj1936.39.3 85, indexed in Pubmed: 14044425.

14. Gegenbaur C. Lehrbuch der Anatomie des Menschen. Wilhelm Engelmann, Leipzig 1883.

15. Gray H. Anatomy of the Human Body. 20th ed. Lea \& Febiger, Philadelphia and New York 1918.

16. Graziotti GH, Rodríguez Menéndez JM, Victorica $\mathrm{CL}$, et al. Systematic study of the internal iliac artery in llama (Lama glama). Ann Anat. 2003; 185(5): 461-463, doi: 10.1016/ s0940-9602(03)80107-3, indexed in Pubmed: 14575273.

17. Honma S, Aimi Y, Kudo M. Ring formation of the internal iliac artery. Surg Radiol Anat. 2013; 35(2): 169-171, doi: 10.1007/ s00276-012-1020-1, indexed in Pubmed: 22968634.

18. Jackson CM. Morris' s treatise on anatomy: A Complete Systematic Treatise by English and American Authors. 5th ed. P. Blakiston's Son, Philadelphia 1914.

19. Jusoh AR, Abd Rahman N, Abd Latiff A, et al. The anomalous origin and branches of the obturator artery with its clinical implications. Rom J Morphol Embryol. 2010; 51(1): 163-166, indexed in Pubmed: 20191138.

20. Kawai K, Honma S, Koizumi M, et al. Inferior epigastric artery arising from the obturator artery as a terminal branch of the internal iliac artery and consideration of its rare occurrence. Ann Anat. 2008; 190(6): 541-548, doi: 10.1016/j.aanat.2008.05.004, indexed in Pubmed: 18706793.

21. Kigata T, Shibata $\mathrm{H}$. Anatomical variations of the arterial branches from the rat iliac arteries. J Vet Med Sci. 2019; 81(1): 1-8, doi: 10.1292/jvms.18-0405, indexed in Pubmed: 30449820.

22. Kochi T, Imai Y, Takeda A, et al. Characterization of the arterial anatomy of the murine hindlimb: functional role in the design and understanding of ischemia models. PLoS One. 2013; 8(12): e84047, doi: 10.1371/journal. pone.0084047, indexed in Pubmed: 24386328.

23. Lipshutz B. A composit study of the hypogastric artery and its branches. Ann Surg. 1918; 67(5): 584-608, doi: 10.1097/00000658-191805000-00012, indexed in Pubmed: 17863918 .
24. Mamatha $H$, Hemalatha $B$, Vinodini $P$, et al. Anatomical study on the variations in the branching pattern of internal iliac artery. Indian J Surg. 2015; 77(Suppl 2): 248-252, doi: 10.1007/s12262-012-0785-0, indexed in Pubmed: 26730003.

25. Mansfield AO, Howard JM. Absence of both common iliac arteries. A case report. Anat Rec. 1964; 150: 363-364, doi: 10.1002/ar.1091500404, indexed in Pubmed: 14248306.

26. Merkel FRJ. Henle's grundriss der anatomie des menschen. 1st ed. Friedrich Vieweg und Sohn, Braunschweig 1988.

27. Nayak SB, Shetty SD, Sirasanagandla SR, et al. Multiple variations in the pelvic vasculature - a case report. J Clin Diagn Res. 2015; 9(2): AD01-AD02, doi: 10.7860/ JCDR/2015/10775.5526, indexed in Pubmed: 25859441.

28. Nickel R, Schummer A, Seiferle E. The Anatomy of the Domestic Animals. Springer-Verlag, Berlin Heidelberg GmbH 1981.

29. Pai MM, Krishnamurthy A, Prabhu LV, et al. Variability in the origin of the obturator artery. Clinics (Sao Paulo). 2009; 64(9): 897-901, doi: 10.1590/S180759322009000900011, indexed in Pubmed: 19759884.

30. Roberts WH, Krishingner GL. Comparative study of human internal iliac artery based on Adachi classification. Anat Rec. 1967; 158(2): 191-196, doi: 10.1002/ar.1091580208, indexed in Pubmed: 6034641.

31. Rusu MC, Cergan R, Motoc AG, et al. Anatomical considerations on the corona mortis. Surg Radiol Anat. 2010; 32(1): 17-24, doi: 10.1007/s00276-009-0534-7, indexed in Pubmed: 19636491.

32. Sakthivelavan S, Aristotle S, Sivanandan A, et al. Variability in the branching pattern of the internal iliac artery in Indian population and its clinical importance. Anat Res Int. 2014; 2014: 597103, doi: 10.1155/2014/597103, indexed in Pubmed: 25580296.

33. Sarikcioglu L, Sindel M, Akyildiz F, et al. Anastomotic vessels in the retropubic region: corona mortis. Folia Morphol. 2003; 62(3): 179-182, indexed in Pubmed: 14507043.

34. Sekiya S, Horiguchi M, Komatsu H, et al. Persistent primitive sciatic artery associated with other various anomalies of vessels. Acta Anat (Basel). 1997; 158(2): 143-149, doi: 10.1159/000147924, indexed in Pubmed: 9311424.

35. Senior HD. The development of the arteries of the human lower extremity. Am J Anat. 1919; 25(1): 54-95, doi: 10.1002/aja.1000250105.

36. Shetty A, Jetti R, Shivaram B, et al. Variant branching pattern of the posterior division of internal iliac artery: a case report. Galle Med J. 2011; 16(2): 37, doi: 10.4038/ gmj.v16i2.3753.

37. Shetty S, Kantha L, Sheshgiri C. Bilateral absence of common iliac artery - a cadaveric observation. Int J Anat Vari. 2013; 6: 7-8, doi: 10.2484/rcr.2008v3i1.47.

38. Tajra J, Lima C, Pires F, et al. Variability of the obturator artery with its surgical implications. J Morphol Sci. 2018; 33(02): 096-098, doi: 10.4322/jms.090015.

39. Talalwah WA, Soames R. Internal iliac artery classification and its clinical significance. Rev Arg de Anat Clin. 2014; 6(2): 63-71.

40. Vazquez N, Ríos C, Sorriba V, et al. Arterial distribution to the pelvic cavity and pelvic limb in the pampas deer (Ozotoceros bezoarticus, Linnaeus 1758). Anat Histol Embryol. 2018; 47(2): 133-139, doi: 10.1111/ahe.12331, indexed in Pubmed: 29205895.

41. Vinnakota S, N B. Trifurcation of posterior division of internal iliac artery: A case report. J Evid Based Med Healthc. 2014; 1(1): 1-4, doi: 10.18410/jebmh/1.

42. Yamaki K, Saga T, Doi Y, et al. A statistical study of the branching of the human internal iliac artery. Kurume Med J. 1998; 45(4): 333-340, doi: 10.2739/kurumemedj.45.333, indexed in Pubmed: 9914720.

43. Yazama $\mathrm{F}$, Hatori $\mathrm{N}$, Kudoh $\mathrm{H}$, et al. Bilateral persistent sciatic arteries in a Japanese man. Anat Sci Int. 2002; 77(2): 128-133, doi: 10.1046/j.0022-7722.2002.00003.x, indexed in Pubmed: 12418093. 